\title{
High-Performance Nanostructured Membrane Electrode Assemblies for Fuel Cells Made by Layer-By-Layer Assembly of Carbon Nanocolloids**
}

\author{
By Marc Michel, André Taylor, Ryan Sekol, Paul Podsiadlo, Peter Ho, Nicholas Kotov, \\ and Levi Thompson
}

Fuel cells are being developed to replace batteries in portable electronic devices and internal combustion engines in automobiles. Key challenges to the commercialization of protonexchange membrane (PEM) fuel cells include high cost and poor durability. One of the primary cost-drivers is the membrane electrode assembly (MEA), which consists of the catalysts, electrolyte membrane, and gas diffusion layers (GDLs). Improving PEM fuel-cell cost and performance will require more efficient utilization of the catalyst and a reduction in the thickness of the MEA membrane, which requires optimization of the nano- and sub-micron structure of the membranes. ${ }^{[1-11]}$

Recently layer-by-layer assembly (LBL) ${ }^{[12]}$ has been used to prepare substructures for PEM fuel cells ${ }^{[13-18]}$ as a tool for balancing different conflicting requirements. LBL makes possible simple incorporation of conductive nanocomponents, conformal coatings of surfaces of any complex geometry, high ionic contents of the multilayers, nanometer-scale control over film thickness, and film porosity. These features make LBL an attractive new technology for fuel-cell assembly. Liu and co-workers reported the fabrication of an electrode-incorporating catalyst in MEA via the reduction of a Pt precursor on the surface of a Nafion membrane, ${ }^{[13]}$ and Farhat and Hammond used LBL-made membranes as a separator of cathode and anode and reached power densities with conventional carbon black (CB) electrodes of $16.5 \mathrm{~mW} \mathrm{~cm}^{-2}$. $^{[18]}$ The LBL assembly of ligand-stabilized platinum nanoparticles was also used to build three-dimensional nanostructured electrodes with a mass-specific activity of $0.11 \mathrm{~A} \mathrm{mg}^{-1} \mathrm{Pt}$ at $0.9 \mathrm{~V}$ for a 5 layer film. ${ }^{[14]}$ Unfortunately, these films were not tested in an actual fuel cell and 5 layer films are somewhat

[*] Dr. M. Michel, Dr. A. Taylor, R. Sekol, P. Podsiadlo, P. Ho, Prof. N. Kotov, Prof. L. Thompson Department of Chemical Engineering University of Michigan 2300 Hayward Street Ann Arbor, MI 48109 (USA) E-mail: lotov@umich.edu

[**] We acknowledge the Fulbright/Alsace committee for financial support. P.P. thanks the Fannie and John Hertz Foundation for support of his research through a graduate fellowship. N.A.K. thanks AFOSR for the support of this research. Supporting Information is available online from Wiley InterScience or form the author. questionable as a functional part of MEA. LBL thin films deposited as a barrier layer on a Nafion membrane were also suggested to be effective for the reduction of methanol cross over for direct methanol fuel cells. ${ }^{[15]}$ LBL multilayers of polyaniline (PANI)/poly(acrylic acid)-co-polyacrylamide (PAA-co-PAAm) film doped with $\mathrm{Pt}$ by reductive precipitation of a Pt salt $\left(\mathrm{H}_{2} \mathrm{PtCl}_{6}\right)$ yielded a maximum Pt loading of $0.3 \mathrm{mg} \mathrm{cm}^{-2}{ }^{[18]}$ Using a somewhat different approach for particle incorporation, carbon-polymer electrodes were constructed using polyelectrolytes and commercially available colloidal dispersions. ${ }^{[18]}$ The electrodes exhibited electronic conductivities of $2-4 \mathrm{~S} \mathrm{~cm}^{-1}$ and ionic conductivities in the range from 10 to $10^{-3} \mathrm{~S} \mathrm{~cm}^{-1}$. Overall, despite the many favorable characteristics of the technique, the performance of the produced PEM and other fuel cells was substantially below the traditional ones with $\mathrm{CB}$, and this can be attributed to suboptimal organization, such as an islandlike distribution of $\mathrm{Pt}$ particles ${ }^{[13]}$ and fairly low conductivities.

In this paper we report the use of carbon-nanotube and -nanofiber composites made by LBL following the technology previously used for making ultrastrong materials ${ }^{[19-21]}$ for PEM fuel cells. The same properties of LBL-made composites that were found very useful for mechanical properties, such as a uniform distribution of nanotubes and nanometer control of the film structure, result in an extensive percolation network and improved electronic and thermal conductivities due to a significant reduction of the tunneling energy required for interparticle charge-hopping step, ${ }^{[22]}$ especially when compared to films produced using other forms of carbon. The LBL technique also affords preparation of composites from carbon nanotubes, ${ }^{[19,20,22,23]}$ nanoparticles, ${ }^{[24-26]}$ and carbon fibers $(\mathrm{CFs})^{[27]}$ with loadings of above $50 \%$ without phase segregation of dissimilar materials. Consequently, a great improvement of the performance and durability is anticipated for the carbon-nanotube- and -nanofiber-based films. In addition, we explored the use of selective heterogeneous nucleation to disperse $\mathrm{Pt}$ onto surfaces of the carbon nanocolloids (Scheme 1).

The triple phase boundary (TPB) regions for the catalyst layer must have be a balance between the ionic and electronic conducting mediums that influence the hydrophilic and hydrophobic properties of the nanocomposite. The porosity of the catalyst film must allow the reactants and products to diffuse through to these TPB regions. In addition, each region 


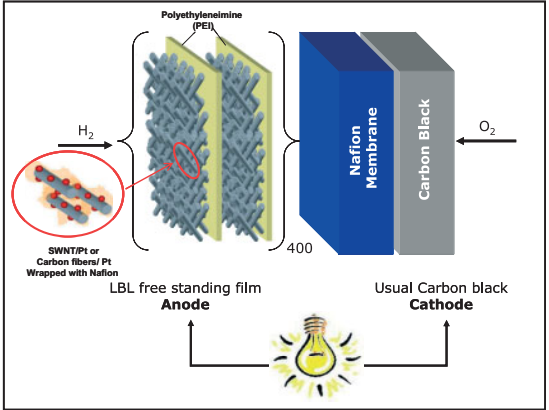

Scheme 1. Outline of steps for the preparation of the LBL films: 1) single-walled nanotube (SWNT) or carbon fiber (CF) before functionalization with Pt nanoparticles, 2) functionalization of SWNT and CF with Pt based on heterogeneous nucleation, 3) wrapping of functionalized CF and SWNT, 4) construction of the LBL film: PEI corresponds to polyethyleneimine (polycation).

must have continuous pathways (i.e. protons to the electrolyte and electrons to the electrode) in order to be effective.

The starting point for the nanoscale design and assembly of the membrane materials is the control of the size of the Pt particles and their tight contact to the carbon nanocolloids. The CFs and single-walled nanotubes (SWNTs) were slightly oxidized, which populated their surfaces with nucleation centers for $\mathrm{Pt}$ nanoparticles during the controlled reduction of $\mathrm{H}_{2} \mathrm{PtCl}_{4}$ (see the Experimental section). After the reduction step, the
CF and SWNT colloid had a desirable configuration of numerous Pt particles fairly uniformly distributed over the entire length of the SWNT or CF, as can be seen in the transmission electron microscopy (TEM) results (Fig. 1), rather than islands of particle clusters. The Pt particles ranged in size from 1.5 to $2.6 \mathrm{~nm}$, which is very suitable for catalytic reactions in PEM and consistent with the results reported by Wang et al. ${ }^{[28]}$

Precipitation of free Pt particles in the solution was not observed, indicating that the particles have a strong bond with the carbon nanocolloids (Fig. 1). X-ray photoelectron spectroscopy (XPS) showed peaks corresponding to $\mathrm{Pt}^{0}$ with no presence of $\mathrm{Cl}$, which indicates complete reduction of $\left[\mathrm{PtCl}_{4}\right]^{2-}$ into $\mathrm{Pt}^{0}$ on the surface of the CF and SWNT supports, namely on [poly(ethyleneimine) $(\mathrm{PEI}) /(\mathrm{Pt} / \mathrm{SWNT}+\mathrm{Nafion})]_{400}$ and $[\mathrm{PEI} /$ $(\mathrm{Pt} / \mathrm{CF}+\mathrm{Nafion})]_{400}$ free standing films (see the Supporting Information). XPS peaks are located at binding energies of $71.2 \mathrm{eV}$ and $74.5 \mathrm{eV}$ for Pt $4 \mathrm{f} 7 / 2$ and Pt5/2, respectively (Fig. 2).

The assembly of MEAs requires composite films of high uniformity and homogeneity, and thus, a highly debundled state of Pt/SWNT and Pt/CF nanocolloids. This state can be very well preserved in $\mathrm{LBL}$ films ${ }^{[19,20,22,27]}$ but not necessarily in other processing techniques. Debundling was achieved by using Nafion as a solubilizing agent for the Pt/SWNT and $\mathrm{Pt} / \mathrm{CF}$ nanocolloids; this is an important result because Nafion is often used in fuel cells. We expect that Nafion's hydrophobic tetrafluoroethylene backbone allows the macromolecule to efficiently wrap around the relatively hydrophobic surfaces
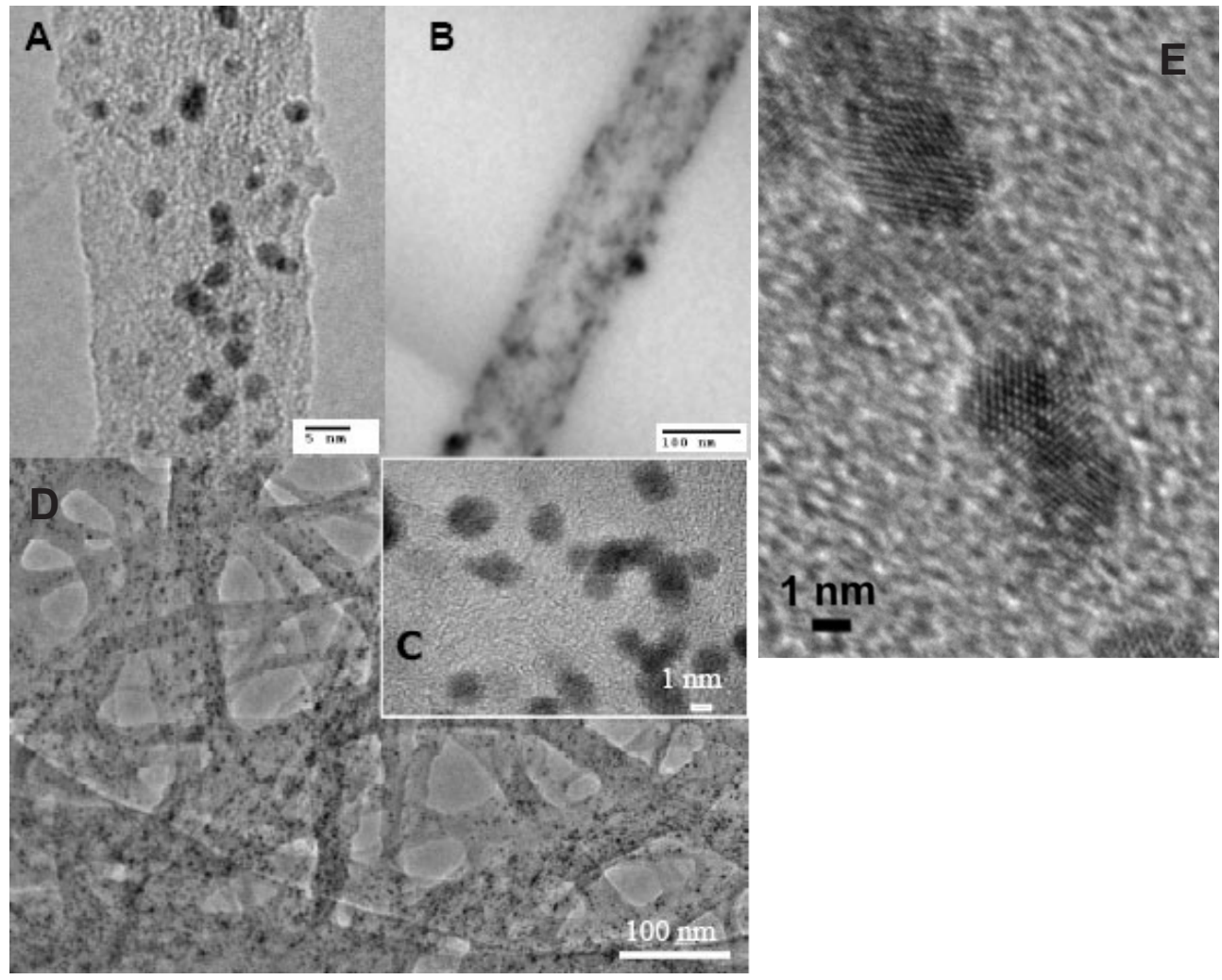

Figure 1. TEM images of A,C,D) Pt/SWNT and B) Pt/CF. 

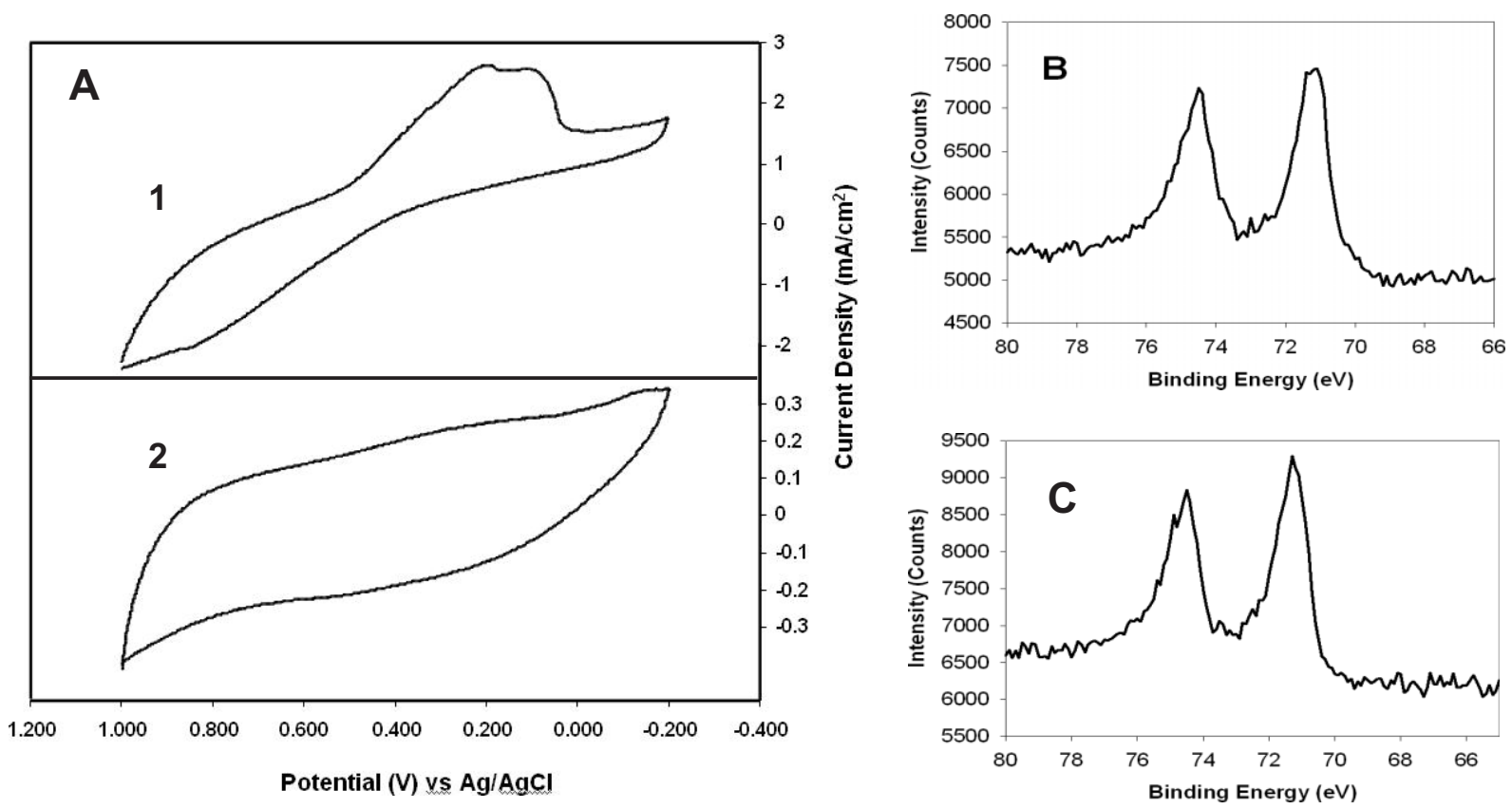

Figure 2. A) Cyclic voltammetry plots for $[\mathrm{PEI} /(\mathrm{Pt} / \mathrm{CF}+\mathrm{Nafion})]_{5}(1)$ and $[\mathrm{PEI} /(\mathrm{Pt} / \mathrm{CF}+\mathrm{Nafion})]_{5}(2)$. Note the difference in the current scales of plots 1 and 2; B) XPS experiments of $[\mathrm{PEI} /(\mathrm{Pt} / \mathrm{CF}+\text { Nafion })]_{400}$ and B) $[\mathrm{PEI} /(\mathrm{Pt} / \mathrm{SWNT}+\text { Nafion })]_{400} \mathrm{LBL}$ film.

of carbon colloids, ${ }^{[29,30]}$ and that sulfonic groups make the entire construct compatible with hydrophilic solvents and make possible efficient ion transport. Dispersions of the Pt/SWNT and $\mathrm{Pt} / \mathrm{CF}$ catalysts were indefinitely stable in $2 \mathrm{mg} \mathrm{mL}^{-1} \mathrm{Na}$ fion in a 70:30 ethanol/water mixture.

The LBL assembly of the C-Pt colloids was accomplished by sequential dipping of glass substrates into Nafion dispersions and positively charged solutions of $1 \mathrm{mg} \mathrm{mL}^{-1}$ of PEI (see the Experimental section). The structure of the assemblies can be abbreviated as $[\mathrm{PEI} /(\mathrm{Pt} / \mathrm{SWNT}+\mathrm{Nafion})]_{n}$ and $[\mathrm{PEI} /(\mathrm{Pt} /$ $\mathrm{CF}+\mathrm{Nafion})]_{n}$, where $n$ corresponds to the number of deposition cycles. The accumulation of C-Pt composite followed the traditional linear LBL pattern although a noticeable increase of the layering increment for higher $n$ (see the Supporting Information) was observed, hinting at a more complicated mechanism. The average thicknesses of the (PEI/(Pt/SWNT+Nafion)) and $(\mathrm{PEI} /(\mathrm{Pt} / \mathrm{CF}+\mathrm{Nafion}))$ bilayers was measured by ellipsometry and estimated to be $(1.7 \pm 0.2)$ and $(3.4 \pm 0.1) \mathrm{nm}$, respectively. The PEI layer thickness is $0.22 \mathrm{~nm}$ for the SWNT and $0.14 \mathrm{~nm}$ for the CF bilayers. The apparently higher thickness of PEI for SWNT may come from greater incorporation in nanopores and cavities of LBL films than on the surface of CFs.

The state of debundling of Pt/SWNT and Pt/CF embedded in the films can be determined by using atomic force microscopy (AFM) and scanning electron microscopy (SEM) examination. The $[\mathrm{PEI} /(\mathrm{Pt} / \mathrm{CF}+\mathrm{Nafion})]_{1-4}$ and $[\mathrm{PEI} /(\mathrm{Pt} /$ SWNT+Nafion) $]_{1-4}$ layers showed single fibers adsorbed on the surface (Fig. 3A-D) with AFM diameters for the Pt/CF and $\mathrm{Pt} / \mathrm{SWNT}$ structures of $40-50 \mathrm{~nm}$ and $1-3 \mathrm{~nm}$, respectively. No bundles of SWNT or CF were observed with diameters beyond twice those for single strands.
The LBL multilayers deposited on the substrate can be released to form free-standing films by exposing the LBL coatings to HF. Such free-standing films can be used in virtually any kind of MEA. The SEM images provide additional information regarding the morphology of the multilayers with high $n$, such as $[\mathrm{PEI} /(\mathrm{Pt} / \mathrm{SWNT}+\mathrm{Nafion})]_{400}$ and $[\mathrm{PEI} /(\mathrm{Pt} / \mathrm{CF}+\mathrm{Na}-$ fion) $]_{400}$. One can see that both the Pt/SWNT and Pt/CF composites are well-packed and uniform (Fig. 4A-D). A high degree of debundling was established in previous publications ${ }^{[19,20,22,27]}$ and can also be distinguished in Figure $4 \mathrm{C}$ and D. The film thicknesses are 3 and $30 \mu \mathrm{m}$, respectively, which corresponds to an average of increment of thickness of 7.5 and $75 \mathrm{~nm}$ per bilayer of SWNT and CF, respectively. These values are higher than those obtained by ellipsometry (see above) for small $n$ because of deviations from the linear character of LBL deposition for high $n$ (see the Supporting Information). We do not think that this deviation has the same nature as exponential $\mathrm{LBL}^{[31]}$ because of restrictions on mobility in the multilayers, but instead changes with the adsorption behavior of the components at high $n$.

As mentioned above, a fuel cell electrode requires three essential properties: electrical conductivity, proton conductivity and efficiency of the catalytic reaction of the Pt particles. From SEM and AFM images, one can also see that they have strong interdigitation and can thus create a dense and extensive 3D network of fibers. This morphology increases the probability of contacts between the strands, while substantial porosity also offers efficient mass transport. The electrical conductivities of the multilayers can be relatively high despite the presence of an insulating polymer matrix. Electrical conductivities were measured on the free-standing $[\mathrm{PEI} /(\mathrm{Pt} / \mathrm{SWNT}+\mathrm{Nafion})]_{400}$ 

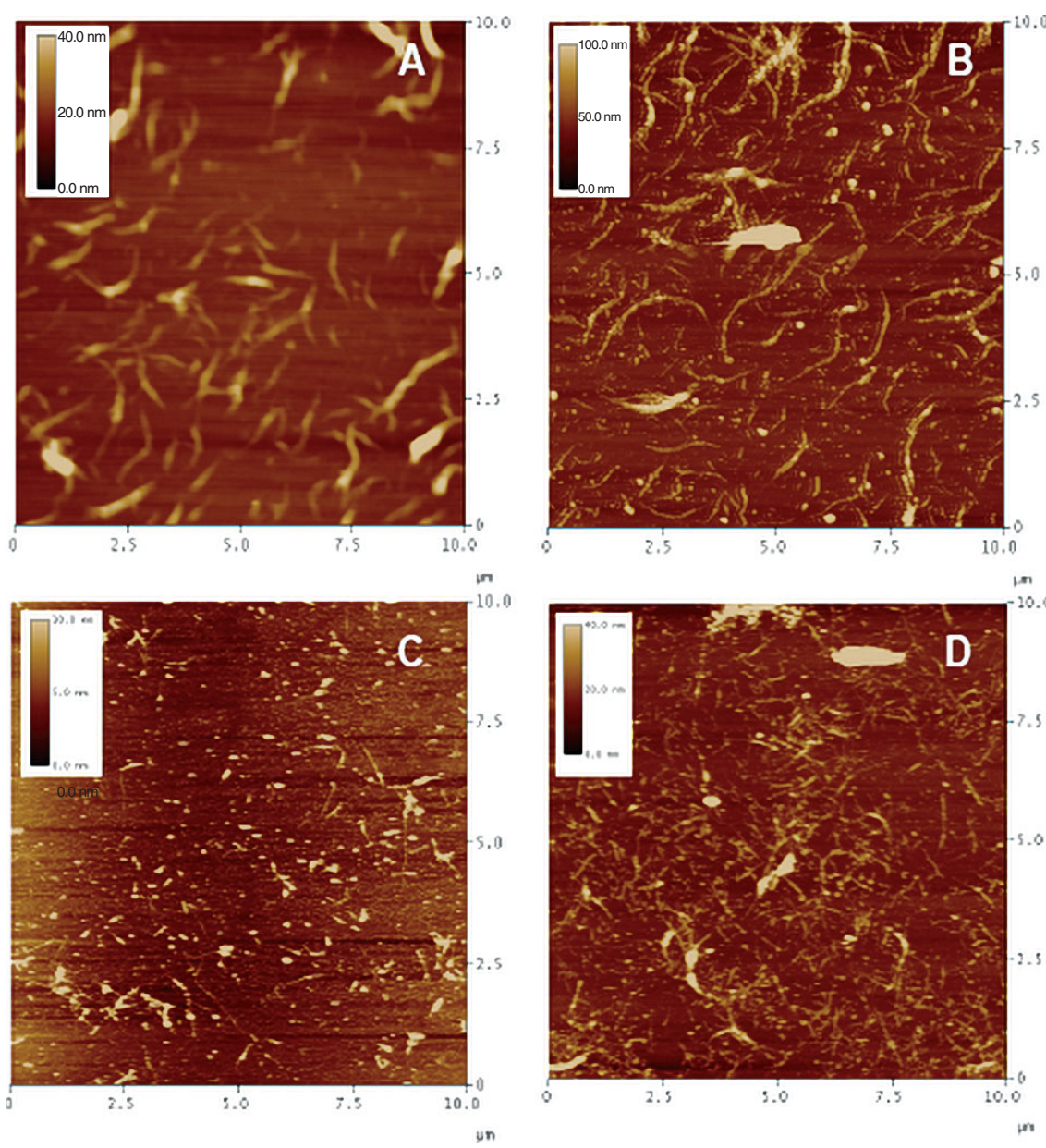

\section{0,0}

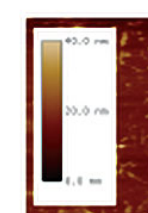

5.0

Figure 3 AFM images of A) $[\mathrm{PEI} /(\mathrm{Pt} / \mathrm{CF}+\mathrm{Nafion})]_{1}$; B) $\left.[\mathrm{PEI} /(\mathrm{Pt} / \mathrm{CF}+\mathrm{Nafion})]_{4} ; \mathrm{C}\right)[\mathrm{PEI} /(\mathrm{Pt} / \mathrm{SWNT}$ $\mathrm{Pt}+\mathrm{Nafion})]_{1} ;$ and D) $[\mathrm{PEI} /(\mathrm{Pt} / \mathrm{SWNT}-\mathrm{Pt}+\mathrm{Nafion})]_{4}$

and $\left[\mathrm{PEI} /(\mathrm{Pt} / \mathrm{CF}+\mathrm{Nafion}]_{400}\right.$ films to be $2.314 \times 10^{2}$ and $2.804 \mathrm{~S} \mathrm{~cm}^{-2}$, respectively. As expected, it is somewhat below most conductive SWNT composites, ${ }^{[2]}$ but sufficient for fuel cells. Importantly, cyclic voltammetry (CV) experiments demonstrated that $\mathrm{Pt}$ particles deposited on nanotubes are indeed active as electrocatalytic centers (Fig. 2A). As one can see, the characteristic $\mathrm{CV}$ peaks corresponding to the electrocatalytic reduction of oxygen on Pt nanoparticles can be clearly distinguished in the CV plots. Also note that the current is substantially higher in the Pt-loaded SWNT films than in the same films without nanoparticles.

The performance of the LBL films was tested in a $\mathrm{H}_{2} / \mathrm{O}_{2}$ fuel cell (Fig. 5). These films were used as the anode and a standard CB-based catalyst with $0.57 \mathrm{mg} \mathrm{Pt} \mathrm{cm}^{-2}$ loading was used as the cathode (see the Experimental section). The freestanding LBL films were hot-pressed onto a Nafion 117 membrane separating the anode and cathode sides.

The fuel cell performance was characterized by peak power densities $\left(\mathrm{W} \mathrm{cm}^{-2}=\mathrm{AV} \mathrm{cm}^{-2}\right)$. For the $[\mathrm{PEI} /(\mathrm{Pt} / \mathrm{SWNT}+\mathrm{Na}-$ fion) $]_{400}$ catalysts it was as high as $195 \mathrm{~mW} \mathrm{~cm}^{-2}$ (Fig. 5A), 10.0 $-10.0$

which is more than an order of magnitude improvement compared to the previously reported LBL films with peak power densities of $17 \mathrm{~mW} \mathrm{~cm}^{-2}$ [32] $^{\text {The }}$ films composed of $\mathrm{CF}$ for the same number of layers, that is, $n=400$, showed even better performance yielding $227 \mathrm{~mW} \mathrm{~cm}^{-2}$ (Fig. 5B). We attribute the better performance of the $\mathrm{CF}$ composite to the higher porosity of the membranes despite their lower electrical conductivity. To our knowledge, the peak power densities of LBL films are the highest values reported so far with the best previous data ranging between 2.5 and $17 \mathrm{~mW} \mathrm{~cm}^{-2}$. $[18,32]$

The amount of $\mathrm{Pt}$ contained in the LBL films can be obtained by completely oxidizing the materials during thermogravimetric analysis (TGA). For the $[\mathrm{PEI} /(\mathrm{Pt} / \mathrm{SWNT}+\mathrm{Nafion})]_{400}$ and $[\mathrm{PEI} /(\mathrm{Pt} / \mathrm{CF}+\mathrm{Nafion})]_{400}$ assemblies, the Pt loadings were $16.9 \%$ and $10.1 \%$, respectively, which corresponds to 0.3 and $0.26 \mathrm{mg} \mathrm{Pt} \mathrm{cm}^{-2}$. These loadings are about 2 times lower than in the usual CB MEA, $0.5 \mathrm{mgPt} \mathrm{cm}^{-2}$, which is very important for decreasing the cost of fuel cells and improving their performance. Note also that LBL films are thinner than the traditional CB MEAs. Pt utilization is one of the key parameters affecting the practical prospects of PEM. For $[\mathrm{PEI} / \mathrm{Pt}-\mathrm{SWNT}+\mathrm{Nafion}]_{400}$ and [PEI/(Pt-CF-+Nafion $]_{400}$ we calculated Pt utilization to be $408 \mathrm{~mW} \mathrm{mg}^{-1} \mathrm{Pt}$ and: $580 \mathrm{~mW} \mathrm{mg}^{-1} \mathrm{Pt}$, respectively. These data are comparable to the best examples of PEM and substantially better that the same parameter for previously reported LBL PEMs, which have their best values in the range of 23.2-33.2 $\mathrm{mW} \mathrm{mg}^{-1} \mathrm{Pt}^{[18,32]}$ Relatively high $\mathrm{Pt}$ utilization indicates that $\mathrm{Pt} / \mathrm{SWNT}$ and $\mathrm{Pt} / \mathrm{CF}$ are well dispersed and organized in the LBL matrix to provide both easy access to $\mathrm{H}_{2}$ and efficient electronic transport from the particles of the catalyst through the dense network of carbon strands.

Although we do not have yet the entire property-structureperformance matrix, which is expected to be quite complex, the promising values of peak power density and $\mathrm{Pt}$ utilization, however, are attributed to the balancing of the diverse requirements of the MEA, and are obtained primarily because of the intrinsically favorable properties of LBL films, such as the uniformity of the particle/fiber distribution, film thinness stimulating mass transfer, and high ionic contents. Further exploitation of these properties combined with a systematic study planned for the next stage of this research could lead to a MEA with exceptional performance. 


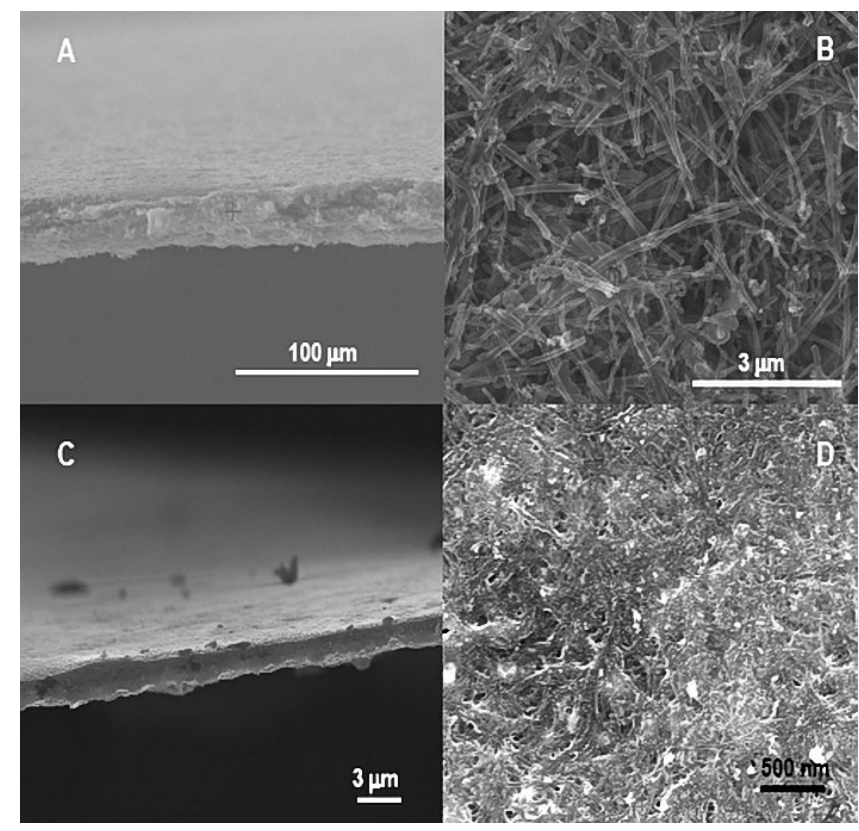

Figure 4. SEM images of $\mathrm{A})$ a cross section of $[\mathrm{PEI} /(\mathrm{Pt} / \mathrm{CF}+\mathrm{Nafion})]_{400}$; B) a top view of $\left.[\mathrm{PEI} /(\mathrm{Pt} / \mathrm{CF}+\mathrm{Nafion})]_{400} ; \mathrm{C}\right)$ a cross section $[\mathrm{PEI} /(\mathrm{Pt} /$ $\mathrm{CF}+$ Nafion $)]_{400}$; and D) a top view of $[\mathrm{PEI} /(\mathrm{Pt} / \mathrm{CF}+\mathrm{Nafion})]_{400}$.

\section{Experimental}

Chemicals: Purified HiPco single-walled carbon nanotubes (impurities: 6-14\%) were purchased from Carbon Nanotechnologies Incorporated (CNI), Houston, Texas. The catalytically grown nanofiber material, Pyrograf III was purchased from Pyrograf Products Inc., (a subsidiary of Applied Sciences Inc., Cedarville, OH). Polyelectrolytes polyethyleneimine [PEI; $\left.M_{\mathrm{W}}=25000\right]$; dihydrogen hexachloroplatinate $\left(\mathrm{H}_{2} \mathrm{PtCl}_{6}\right)$ and sodium dodecyl sulfate (SDS) were all obtained from Sigma-Aldrich Co. Platinum, nominally $20 \%$ on CB (HiSPECTM 3000) was obtained from Alfa Aesar, a Johnson Matthey Company. All solutions were made in $18 \mathrm{M} \mathrm{Ohm} \mathrm{deionized} \mathrm{(DI)}$ water obtained from a Barnstead E-pure system. Nafion 117 (5\% resin solution) used for the carbon dispersions was obtained from Fluka. Nafion perfluorinated ion-exchange resin, $5 \mathrm{wt} \%$ solution in a lower aliphatic alcohols $/ \mathrm{H}_{2} \mathrm{O}$ mix used for the standard fuel cell catalyst blend was obtained from Aldrich. Teflon emulsion, PTFE 30, was purchased from Fuel Cell Scientific, Stoneham, MA. Nafion 117 membranes made by Dupont were purchased from Ion Power, New Castle DE. The Nafion 117 membrane was treated according to a standard procedure: To remove organic impurities and to obtain the $\mathrm{H}^{+}$form for use in the polymer electrolyte membrane fuel cell (PEMFC) the membranes were pretreated by boiling in $50 \mathrm{vol} \% \mathrm{HNO}_{3}$ and DI water for $1 \mathrm{~h}$, and rinsed in boiling DI water for $30 \mathrm{~min}$, boiling in $0.5 \mathrm{M} \mathrm{H}_{2} \mathrm{SO}_{4}$ solution for $30 \mathrm{~min}$, and boiling twice in DI water for $30 \mathrm{~min}$. The membranes were subsequently stored in DI water until ready for use. Fuel cell gas diffusion layers (GDL) used were (ELAT V3.1 double side automated) purchased from E-TEK, the fuel cell division of PEMEAS, Somerset, NJ.

Instrumentation: Sonication was performed in a VWR Model 150 HT ultrasonic cleaner. Thermal gravimetric (Model SDT Q600 Instrument, TA Instruments, Inc.) analysis was used to determine actual loadings of the prepared catalysts. Experiments were conducted by increasing the sample temperature to $1000^{\circ} \mathrm{C}$. Step-like reductions in mass were observed at approximately $420^{\circ} \mathrm{C}$, when the carbon supports started to be consumed, leaving the Pt particles behind. At $1000^{\circ} \mathrm{C}$ it was assumed that all the carbon support had been removed from the sample and only oxidized Pt particles remained as PtO. Catalyst loadings were then calculated based on the initial mass of the $\mathrm{Pt} /$ $\mathrm{C}$ nanocomposite and final mass of the remaining $\mathrm{PtO}$ particles. The amount of Pt in the LBL films was measured in the same way by assuming that all the polyelectrolytes (Nafion, PEI) were completely burned off at $1000^{\circ} \mathrm{C}$. SEM was accomplished using a Philips XL30 field-emission gun scanning electron microscope and an FEI Nova Nanolab dual-beam focused ion-beam (FIB). TEM was accomplished using a JEOL 3011 high-resolution electron microscope. AFM was accomplished using a Nanoscope III (Digital Instruments/Veeco Metrology Group). XPS was performed using a Kratos Axis Ultra X-ray photoelectron spectrometer. UV-vis absorption measurements were taken using an Agilent 8453E UV-vis spectrometer. A model 273 potentiostat from EG\&G Princeton Applied Research (PAR) was used for electrochemical measurements. For $\mathrm{CV}$ experiments, a BAS potentiostat was used.

Preparation of Pt-loaded SWNT and CF: The same procedure was used to prepare the SWNT- and CF-supported catalysts. Before functionalization, the SWNT and CF supports were oxidized in a sonicated solution of $\mathrm{HNO}_{3}$ for $1 \mathrm{~h}$ (VWR Model $150 \mathrm{HT}$ ultrasonic cleaner) at ambient conditions. The resulting materials were filtered, rinsed several times with ethanol and dried at $60^{\circ} \mathrm{C}$ under vacuum for $24 \mathrm{~h}$ Chloroplatinic acid $\left(\mathrm{H}_{2} \mathrm{PtCl}_{6}\right)$ was used as the platinum precursor, and ethylene glycol (EG) as the solvent and a soft reducing agent. Sodium dodecyl sulfate (SDS) was added to the reaction system and dissolved by mixing. The oxidized SWNT or CF $(100 \mathrm{mg})$ were mixed with a solution of SDS $(2 \%)$ in EG $(200 \mathrm{~mL})$. After ultrasonication
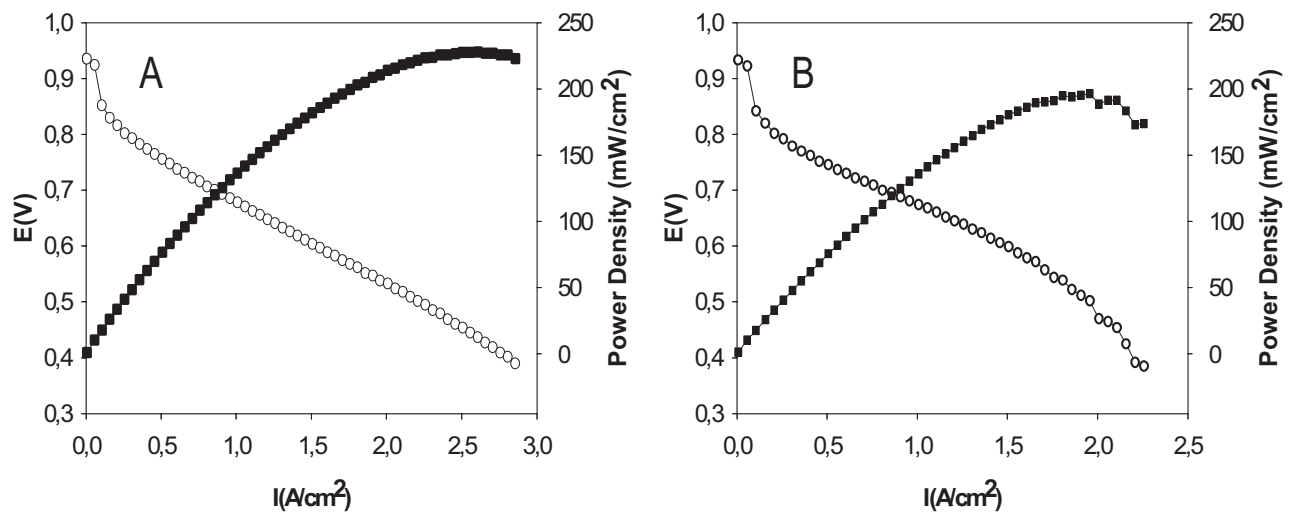

Figure 5. Polarization $(\bigcirc)$ and power density $(\bullet)$ curves of fuel cells with $L B L$ film anodes: $A)[P E I /(P t / C F+N a f i o n)]_{400}$ and $\left.B\right)[P E I /(P t / S W N T+N a-$ fion $]_{400}$. The fuel cell temperature was $80^{\circ} \mathrm{C} . \mathrm{H}_{2}$ and $\mathrm{O}_{2}$ flows on the fuel cell saturators were set at $100 \mathrm{sccm}$ flow rates, $100 \%$ relative humidity, and $90^{\circ} \mathrm{C}$ temperature. 
of the mixture for $1 \mathrm{~h}$, a solution of $\mathrm{H}_{2} \mathrm{PtCl}_{6}\left(0.5 \mathrm{~g} \mathrm{~mL}^{-1}\right)$ in $\mathrm{EG}$ $(20 \mathrm{~mL})$ was added with constant agitation. The mixture was then heated to $150{ }^{\circ} \mathrm{C}$, and aged for $30 \mathrm{~min}$ with vigorous agitation to ensure completion of the reaction. The products were filtrated, rinsed several times with ethanol and dried at $60^{\circ} \mathrm{C}$ under vacuum for $24 \mathrm{~h}$. The functionalized SWNT and CF are referred to as Pt/SWNT and $\mathrm{Pt} / \mathrm{CF}$.

Preparation of Carbon-Polyelectrolyte Nanocolloids and LBL Deposition: Functionalized $\mathrm{Pt} / \mathrm{SWNT}$ and $\mathrm{Pt} / \mathrm{CF}$ were dispersed in a solution of $2 \mathrm{mg} \mathrm{mL}^{-1}$ of Nafion in ethanol/water (70:30) with $30 \mathrm{~min}$ of ultrasonication. These dispersions were used for one LBL component. PEI solution $\left(1 \mathrm{mg} \mathrm{mL}^{-1}\right)$ was prepared for another LBL partner. The procedures of LBL assemblies of SWNT and CF resembled those described in previous publications [19-22,27]. Briefly, the (Pt/SWNT or $\mathrm{Pt} / \mathrm{CF}$ )+Nafion nanocomposites were assembled onto solid supports by alternate dipping of a solid substrate (glass slides or silicon wafers) into dispersions of carbon nanocolloids and polyelectrolyte solutions. The wafers/slides were cleaned with piranha solution (a 1:3 mixture of $30 \% \mathrm{H}_{2} \mathrm{O}_{2}$ and concentrated $\mathrm{H}_{2} \mathrm{SO}_{4}$; (Note-this is a dangerous mixture that violently reacts with organics); rinsed in DI water, sonicated for $15 \mathrm{~min}$ and again thoroughly rinsed with DI water. They were then coated with a PEI precursor layer. The $1 \%$ PEI solution was at $\mathrm{pH}$ 8.5. The layer sequence of PEI [Nafion/(Pt/SWNT or Pt/CFs)] was repeated until the desirable thickness was obtained. Exposure times of $10 \mathrm{~min}$ were used for polyelectrolytes and (SWNT or CF) baths. Through charge-transfer interactions between the Nafion wrapped around the SWNT or CF and the polycation (PEI), an LBL assembly on a charged substrate (glass or $\mathrm{Si}$ ) was formed. Each LBL-layering cycle consists of the following steps: $10 \mathrm{~min}$ dip in PEI $\left(1 \mathrm{mg} \mathrm{mL}^{-1}\right)$, 3 min rinse in DI water $\left(\mathrm{H}_{2} \mathrm{O}\right), 10 \mathrm{~min}$ drying under $\mathrm{N}_{2}, 10 \mathrm{~min}$ dip in $\mathrm{Pt} / \mathrm{SWNT}$ or $\mathrm{Pt} / \mathrm{CFs}$ dispersed in Nafion, a 3 min rinse in DI water $\left(\mathrm{H}_{2} \mathrm{O}\right)$, and 10 min drying under $\mathrm{N}_{2}$.

The assembly conditions of the entire procedure (such as $\mathrm{pH}$, ionic strengths, and concentrations) were optimized so that the dipping cycles could be repeated as many times as needed with linear growth of the multilayers. Multilayered nanocomposite stacks with a cumulative structure of [(PEI-(Pt/SWNT or Pt/CFs) + Nafion] containing $400 \mathrm{bi}-$ layers, were typically used in this study. An example notation of the LBL assembly is [polycation/(catalyst + polyanion) $]_{n}$ where $n$ represents the number of repeated dipping processes (bilayer) in the different solutions. Hence a representative LBL film is $[\mathrm{PEI} / \mathrm{Pt} /$ SWNT+Nafion) $]_{400}$ : this represents a 400 bilayer nanocomposite film consisting of PEI, Pt functionalized single-walled carbon nanotubes, and Nafion.

For CV experiments, 10-15 LBL bilayers were made. The files were made so that the thickness of the coatings with and without Pt was the same. $0.1 \mathrm{M} \mathrm{H}_{2} \mathrm{SO}_{4}$ was used as a buffer. Different scan rates from 500 to $5 \mathrm{mV} \mathrm{s}^{-1}$ were used, but $50 \mathrm{mV} \mathrm{s}^{-1}$ gave the most pronounced $\mathrm{CV}$ features.

MEA construction and Fuel Cell Testing: The standard catalyst ink solutions were made from Hispec3000TM Pt/C with $20 \% \mathrm{Pt}$ loading. The cathode catalyst layers were made from an ink solution made of $\mathrm{Pt} / \mathrm{C}$ (68\%), Nafion (20\%), and PTFE (12\%). The ink solutions were painted onto the GDLs using a hand painting (screen printing) technique until the desired Pt loading was achieved. The Pt loading of the cathode layers was ca. $0.5 \mathrm{mg} \mathrm{cm}^{-2}$.

Free-standing LBL films were used as anodes. They were placed between the GDL and the Nafion 117 membrane forming the anode layer. The Pt loading of the LBL layers was determined using TGA. The MEAs were made by hot-pressing Nafion 117 membrane between the anode layer and cathode layer at $135^{\circ} \mathrm{C}$ for $5 \mathrm{~min}$ at a pressure of $10 \mathrm{MPa}$. The MEAs were tested in a single fuel cell housing and were conditioned overnight until a steady state current was achieved at a potential of $0.6 \mathrm{~V}$. The temperature of the fuel cell was $80^{\circ} \mathrm{C}$ and the anode and cathode saturators were set at $90^{\circ} \mathrm{C}$. The flow rates of the humidified hydrogen and oxygen were set at $100 \mathrm{sccm}$. An agilent electronic load controlled the cell potential and a National Instruments Data acquisition system controlled the inputs. The operation of the fuel-cell test station was controlled and moni- tored by LabView programs written by the second author. The data presented in this work are not corrected for internal resistance.

Received: May 19, 2007

Revised: July 6, 2007

Published online: October 31, 2007

[1] M. P. Hogarth, T. R. Ralph, Platinum Metals Review 2002, 46, 146.

[2] M. Uchida, Y. Fukuoka, Y. Sugowara, H. Ohara, A. Ohta, J. Electrochem. Soc. 1998, 145, 3708.

[3] S. D. Thompson, L. R. Jordan, M. Forsyth, Electrochimica Acta 2001, 46, 1657.

[4] T. Matsumoto, T. Komatsu, H. Nakano, K. Arai, Y. Nagashima, E. Yoo, T. Yamazaki, M. Kijima, H. Shimizu, Y. Takasawa, J. Nakamura, Catalysis Today 2004, 90, 277.

[5] M. M. Waje, X. Wang, W. Z. Li, Y. S. Yan, Nanotechnology 2005, 16 , S395.

[6] C. Wang, M. Waje, X. Wang, J. M. Tang, R. C. Haddon, Y. Yan, Nano Lett. 2004, 4, 345.

[7] X. Wang, M. Waje, Y. S. Yan, Electrochem. Solid-State Lett. 2005, 8, A42.

[8] T. Matsumoto, Y. Nagashima, T. Yamazaki, J. Nakamura, Electrochem. Solid-State Lett. 2006, 9 , A160.

[9] S. H. Joo, S. J. Choi, I. Oh, J. Kwak, Z. Liu, O. Terasaki, R. Ryoo Nature 2001, 412, 169

[10] G. L. Che, B. B. Lakshmi, E. R. Fisher, C. R. Martin, Nature 1998 $393,346$.

[11] S. Srinivasan, O. A. Velev, A. Parthasarathy, D. J. Manko, A. J. Appleby, J. Power Sources 1991, 36, 299.

[12] G. Decher, Science 1997, 277, 1232.

[13] M. Pan, H. L. Tang, S. P. Jiang, Z. C. Liu, J. Electrochem. Soc. 2005, 152, A1081.

[14] C. N. Kostelansky, J. J. Pietron, M. S. Chen, W. J. Dressick, K. E. Swider-Lyons, D. E. Ramaker, R. M. Stroud, C. A. Klug, B. S. Zelakiewicz, T. L. Schull, J. Phys. Chem. B 2006, 110, 21487.

[15] S. P. Jiang, Z. Liu, Q. Tian, Adv. Mat. 2006, 18, 1068

[16] T. R. Farhat, P. T. Hammond, Adv. Funct. Mater. 2005, 15, 945.

[17] T. R. Farhat, P. T. Hammond, Chem. Mat. 2006, 18, 41.

[18] T. Farhat, P. T. Hammond, Adv. Funct. Mat. 2006, 16, 433.

[19] A. A. Mamedov, N. A. Kotov, M. Prato, D. Guldi, J. P. Wicksted, A. Hirsch, Nat. Mater. 2002, 1, 190.

[20] M. Olek, J. Ostrander, J. Jurga, H. Möhwald, N. A. Kotov, K. Kempa, M. Giersig, Nano Lett. 2004, 4, 1889.

[21] Z. Tang, N. A. Kotov, S. Magonov, B. Ozturk, Nat. Mater. 2003, 2, 413.

[22] B. S. Shim, Z. Y. Tang, A. Morabito, N. A. Kotov, A. Agarawal, H. Hong, N. A. Kotov, Chem. Mater. 2007, in press.

[23] B. S. Shim, N. A. Kotov, Langmuir 2005, 21, 9381.

[24] a) A. Mamedov, J. W. Ostrander, F. Aliev, N. A. Kotov, Langmuir 2000, 16, 3941. b) D. S. Koktysh, X. Liang, B.-G. Yun, I. PastorizaSantos, R. Matts, M. Giersig, C. Serra-Rodríguez, L. Liz-Marzan, N. A. Kotov, Adv. Funct. Mater. 2002, 12, 255.

[25] A. Mamedov, N. A. Kotov, Langmuir 2000, 16, 5530.

[26] A. Rogach, D. Koktysh, M. Harrison, N. A. Kotov, Chem. Mater 2000, $12,1526$.

[27] B. S. Shim, J. Starkovich, N. Kotov, Compos. Sci. Technol. 2006, 6, 1174.

[28] Y. Wang, X. Xu, Z. Tian, Y. Zong, H. Cheng, C. Lin, Chem. Eur. J. 2006, $12,2542$.

[29] V. A. Sinani, M. K. Gheith, A. A. Yaroslavov, A. A. Rakhnyanskaya, K. Sun, A. A. Mamedov, J. P. Wicksted, N. A. Kotov, J. Am. Chem. Soc. 2005, 127, 3463

[30] J. Wang, M. Musameh, Y. H. Lin, J. Am. Chem. Soc. 2003, 125, 2408.

[31] a) C. Picart, Ph. Lavalle, P. Hubert, F. J. G. Cuisinier, G. Decher, P. Schaaf, J.-C. Voegel, Langmuir 2001, 17, 7414. b) C. Picart, J. Mutterer, L. Richert, Y. Luo, G. D. Prestwich, P. Schaaf, J.-C. Voegel, P. Lavalle, Proc. Natl Acad. Sci. USA 2002, 99, 12531.

[32] J. L. Lutkenhaus, P. T. Hammond, Soft Matter 2007, 3, 804. 